\title{
Effects of Antipsychotics on Bone Mineral Density in Patients with Schizophrenia: Gender Differences
}

\author{
Chien-Yu Chen ${ }^{1}$, Hsien-Yuan Lane ${ }^{2}$, Chieh-Hsin Lin $^{3}$ \\ ${ }^{1}$ Department of Psychiatry, Kaohsiung Chang Gung Memorial Hospital, Chang Gung University College of Medicine, Kaohsiung, ${ }^{2}$ Institute \\ of Clinical Medical Science and ${ }^{3}$ Department of Psychiatry, China Medical University Hospital, Taichung, Taiwan
}

\begin{abstract}
Low bone mineral density (BMD) and osteoporosis are common in patients with schizophrenia and detrimental to illness prognosis and life quality. Although the pathogenesis is not fully clear, series of studies have revealed factors related to low BMD such as life style, psychotic symptoms, medication use and the activity of bone absorption markers. It has been known that antipsychotic-induced hyperprolactinemia plays a critical role on decreased BMD. However, it remains uncertain whether the risk factors differ between men and women. According to the effect on prolactin, antipsychotics can be classified into two groups: prolactin-sparing (PS) and prolactin-raising (PR). Our previous study has demonstrated that clozapine which is among the PS antipsychotics is beneficial for BMD when compared with PR antipsychotics in women with chronic schizophrenia. We have also found that risks factors associated with low BMD are different between men and women, suggesting that gender-specific risk factors should be considered for intervention of bone loss in patients with schizophrenia. This article reviews the effects of antipsychotics use on BMD with particular discussion for the differences on gender and age, which implicate the alterations of sex and other related hormones. In addition, currently reported protective and risk factors, as well as the effects of medication use on BMD including the combination of antipsychotics and other psychotropic agents and other potential medications are also reviewed.
\end{abstract}

KEY WORDS: Schizophrenia; Bone density; Gender effects; Antipsychotics agents; Hyperprolactinemia.

\section{INTRODUCTION}

\section{Prevalence of Osteoporosis and Osteopenia in Patients with Schizophrenia}

The effects on life quality and prognosis of lower bone mineral density (BMD) and osteoporosis as to bone fracture $^{1,2)}$ among schizophrenia patients receiving antipsychotics had earned attention gradually during this decade. ${ }^{3)}$ Patients with schizophrenia have 54\% increased risk of mortality after a major fracture than control group. ${ }^{4)}$ Besides, the vital impact of hip fractures in schizophrenia patient is stated, which would cause worsening mental state and ambulatory, ${ }^{5)}$ higher rate of postoperative infection and a risk of contra-lateral fractures. ${ }^{6,7)}$ Osteoporosis is defined as "a systemic skeletal disease characterized by low bone density and micro-architectural

\footnotetext{
Received: November 24, 2015 / Revised: February 6, 2016

Accepted: February 11, 2016

Address for correspondence: Chieh-Hsin Lin, MD, PhD

Department of Psychiatry, Kaohsiung Chang Gung Memorial Hospital, No. 123, Da-Pi Road, Niao-Sung District, Kaohsiung 803, Taiwan Tel: +886-918-996908, Fax: +886-7-7326817

E-mail: cyndi36@gmail.com
}

deterioration of bone tissue, with a consequent increase in bone fragility and susceptibility to fracture.",8) The standard method assessing BMD is dual-energy X-ray absorptiometry (DEXA), that DEXA of the femur may represent actual bone strength." ${ }^{9)}$ According to the World Health Organization (WHO) definition, osteoporosis stands for the condition of patient's femoral neck BMD was 2.5 standard deviations (SDs) below the mean of a young and healthy population (T-score), matched for gender and ethnic group. Z-score was defined similarly to T-score, but the mean BMD was from an age-matched adult reference population. ${ }^{10)}$ Low BMD, or osteopenia, was defined as a BMD value more than 1 SD but $<2.5$ SDs. ${ }^{11)}$ Previous studies indicated that $32-65 \%$ of patients treated with antipsychotics suffer from osteopenia, which may lead to osteoporosis ${ }^{12,13)}$ A recent meta-analysis on decreased BMD in schizophrenia patients revealed that the overall pooled prevalence of osteopenia was $40.0 \%$ and osteoporosis was $13.2 \%{ }^{6}{ }^{6}$ The prevalence rates of osteopenia and osteoporosis differ from ages and genders. A report of 965 chronic schizophrenia patients indicated that $44 \%$ men and $48.9 \%$ women have osteopenia while $9.2 \%$ men and $21 \%$ women

(c) This is an Open-Access article distributed under the terms of the Creative Commons Attribution Non-Commercial License (http://creativecommons.org/licenses/by-nc/4.0) which permits unrestricted non-commercial use, distribution, and reproduction in any medium, provided the original work is properly cited. 
have osteoporosis. ${ }^{14)}$ The above evidences pointed out that schizophrenia patient had significantly increased risk of low BMD comparing with healthy controls. ${ }^{4,6,12-14)}$ The underlying mechanisms, risk/protective factors, gender differences and medication effects need to be discussed.

\section{The Effects of Hyperprolactinemia and Hypogonadism on Bone Metabolism}

Dopamine is synthesized in the tubero-infundibular neurons of the hypothalamus. It is transported to the pituitary by the portal hypophyseal circulation. Most antipsychotics, as D2 receptor antagonists, bind to the D2 receptors of lactotroph cell in the pituitary would lead to the release of prolactin ${ }^{15)}$ and subsequent hyperprolactinemia, a sustained prolactin elevation above normal laboratory level. The usual normal prolactin levels in peripheral blood are below $530 \mathrm{mIU} / \mathrm{L}(25 \mathrm{ng} / \mathrm{ml})$ in women and 424 $\mathrm{mIU} / \mathrm{L}(20 \mathrm{ng} / \mathrm{ml})$ in men. ${ }^{16)}$ The BMD is decreased by $15-30 \%$ in hyperprolactinemia women compared with control groups. ${ }^{17)}$ Nevertheless, high levels of prolactin inhibit the release of gonadotropin releasing hormone (GnRH) from the hypothalamus, resulting in impaired secretion of the luteinizing hormone and follicle-stimulating hormone, which consecutively lower the gonadal hormone secretion. ${ }^{18)}$ Studies suggest that high prolactin levels affect bone metabolism by reducing sex hormone levels. ${ }^{19,20)}$ Estrogen promotes osteocytes and osteoblasts directly and has inhibitory effect on osteoclasts. ${ }^{21)}$ It also affects the synthesis of 25-OH-vitamin D and the absorption of calcium in the intestine. ${ }^{12,22)}$ Therefore, withdrawal of estrogen leads to an enhancement of osteoclast activity which is not completely compensated by a collateral increase in osteoblast activity, ${ }^{23)}$ meanwhile, the decrease of progesterone no longer facilitate bone formation by stimulating osteoblast. ${ }^{24)}$ Furthermore, prolactin has been observed to directly decrease osteoblast cell numbers by reduced proliferation, thus providing a "direct effect" mechanism explaining the reduction of BMD. ${ }^{25}$ )

\section{Other Risk Factors for Decreased BMD in Patients with Schizophrenia}

WHO recognized several factors associated with decreased BMD, including smoking ${ }^{26)}$ lower body mass in$\operatorname{dex}(\mathrm{BMI}),{ }^{12)}$ although recent evidence showed that obesity is a risk factor of low BMD, ${ }^{27)}$ lack of exercise, ${ }^{28)}$ alcohol consumption, ${ }^{29)}$ glucocorticoid use, ${ }^{30)}$ family history, ${ }^{31)}$ prior fracture ${ }^{32)}$ and poor nutrition. ${ }^{33,34)}$ Among the above reported factors, a review article found only 2 significant correlations: decreased BMD and lower BMI,
BMD at the 4th lumbar spine and smoking. ${ }^{35)}$ Nevertheless, prospective studies that focus on schizophrenia are needed to verify the contribution of each risk factor as well as the interaction among different factors.

Beside the above mentioned risk factors, schizophrenia patients are at higher risk for decreased BMD and fractures for the disorder per se and its related health problems. ${ }^{4,36}$ Risk factors of decreased BMD specific to schizophrenia include lower levels of physical activity ${ }^{37}$ and sedentary lifestyle, vulnerability to metabolic syndrome $^{27,38)}$ and diabetes mellitus ${ }^{39)}$ polydipsia which is related to excessive calcium loss, ${ }^{40)}$ vitamin D deficiency resulting from inadequate diet and insufficient sun exposure, ${ }^{41,42)}$ high smoking prevalence rate with greater frequency of heavy smoker than control group ${ }^{43,44)}$ which dysregulated calciotropic as well as sex hormone and imbalanced the receptor activator of nuclear factor-kappaB ligand (RANKL)-RANK-osteoprotegerin (OPG) system, ${ }^{45)}$ and excessive alcohol intake. ${ }^{46,47)}$ Among the aforementioned factors, both pathological alcohol drinking and diabetes may also increase the risk of falling and subsequent fracture. ${ }^{48)}$ The motor incoordination commonly seen in patients with schizophrenia ${ }^{49)}$ could also lead to the increased risks of falling and fracture.

Schizophrenia itself may also be an independent determinant of osteoporosis. A cross-sectional study in 28 women and 20 men with schizophrenia compared with 6,100 control population found that schizophrenia was an independent risk factor of osteoporosis in women but not in men after controlling other risk factors including vitamin D status, and medications. ${ }^{50)}$ However, the finding might be limited by its relatively small sample size of male schizophrenia patients.

\section{Different Measurements, Definition of Bone Mineral Density/DEXA Z Score than T Score}

According to the National Institutes of Health Consensus Development Panel on Osteoporosis in 2001, osteoporosis is defined as "a skeletal disorder characterized by compromised bone strength predisposing a person to an increased risk of fracture. ${ }^{, 51)}$ Since the introduction of DEXA in the late 1980s, acquisition time was dramatically shortened and the accuracy and precision of BMD measurement improved. ${ }^{52)}$ In 1994, the mean BMD of a young and healthy population was recommended by the WHO as a comparison in diagnosing osteoporosis. T scores were derived from the comparison with the healthy adult population. Osteopenia was defined by an absolute BMD value, $T$ score, between -2.5 and $-1,{ }^{53)}$ and osteo- 
porosis was defined by a $\mathrm{T}$ score of -2.5 or lower. $^{54)}$ Later, the International Society for Clinical Densitometry (ISCD) suggested physicians to use Z-score, rather than T-score, for diagnosing low bone mass in children, premenopausal women, and men younger than 50 years. ${ }^{11,55-57)} \mathrm{Z}$ score is of help for determining whether bone mineral loss results from aging. ${ }^{58)}$ Nevertheless, Z-scores are currently lack of sufficient reliability due to the lack of standardization of definition and calculation techniques as well as developing an ethnicity-matched reference population. ${ }^{57,59)}$

\section{GENDER DIFFERENCES}

\section{Gender Difference about Effects of Hormone on Bone Metabolism}

Men have a higher level of peak bone density than women among aged 20-29 years that prevents the exacerbation of osteopenia or osteoporosis. ${ }^{60,61)}$ Testosterone exerts effect on increment and perseveration on bone trabecular number and is fundamental in bone maturation, ${ }^{62)}$ thereby is negatively correlated with osteoporosis in men. ${ }^{12)}$ However, BMD is related more to estradiol than to testosterone in elderly men. ${ }^{62-66)}$ Testosterone is also associated with the level of 25-hydroxylation of vitamin D that is related to Leydig cells recently found to be involved in bone-testis endocrine loop. ${ }^{67)}$ Simultaneous reduction of sex hormones and vitamin D was associated with 4-fold risk of a major osteoporotic fracture. ${ }^{68)}$ In both men and women, bio-available testosterone plays a role in preventing low BMD via converting into estradiol by aromatase. ${ }^{69-71)}$ However, in patients with hypogonadism, testosterone replacement alone did not improve BMD greatly $^{72)}$ and the effect of testosterone was uncertain. ${ }^{69)}$ Research regarding estrogen receptor and aromatase deficiency suggests that estrogen plays important role in BMD in men. ${ }^{73,74)}$ Lower level of estradiol was associated with an increased risk of fracture in men. ${ }^{69)}$

Women's BMD is highest in their early to the mid-30s, which declines in greater extend in the first 3 to 5 years of menopause. In premenopausal women, the findings of sex hormones effect on BMD were inconsistent. A study showed that androgen level was positively related to BMD among premenopausal women. ${ }^{75)}$ Serum bioavailable testosterone was also found to be a significant independent predictor for BMD of premenstrual women in another study. ${ }^{76)}$ A review article indicated that combined estrogen and testosterone therapy increased BMD in premenopausal women to a greater degree than estrogen therapy alone. ${ }^{77)}$ Whether estrogen plays a more important role than testosterone on BMD in premenstrual women remains inconclusive due to limited reports. The post-menopausal effect on schizophrenic women and the effect of prophylactic hormone replacement therapy would be discussed later.

\section{Gender Difference of Antipsychotic Effect on Bone Mineral Density}

Antipsychotic drugs can be categorized into 2 groups: prolactin-sparing (PS) group, including olanzapine, quetiapine, aripiprazole, ziprasidone and clozapine, and prolactin-raising (PR) group, including all first-generation antipsychotics, amisulpride, risperidone and paliperidone. ${ }^{78)}$ Table 1 summarized articles that discussed gender difference of antipsychotic effect on BMD as well as comparison of antipsychotics agent and hyperprolactinemia with decreased BMD. A cross-sectional study in 195 Taiwanese schizophrenia patients pointed out that both women and men taking PS antipsychotics have higher BMD than those taking other antipsychotics (including PR antipsychotics and combination of PS and PR antipsychotics). ${ }^{79)}$ A study in 16,341 hip fracture patients based on the General Practice Research Database found the association between PR antipsychotics use and hip fractures in both gender. ${ }^{2)}$

A literature review pointed out that the prevalence of hyperprolactinemia is the highest in women using risperidone and amisulpride (around 80-90\%) than other antipsychotic drugs. Amisulpride caused hyperprolactinemia in almost all cases and the prolactin level was significantly higher in female than male patients. The dose of antipsychotic drugs was not correlated with the prolactin level. ${ }^{80)}$ The prolactin levels did not differ between the pre- and post-menopausal women. ${ }^{24)}$ A large point-prevalence study in 402 schizophrenia patients also revealed that hyperprolactinemia was more common among females than male patients taking risperidone $(88 \%$ vs. $47.6 \%$, respectively; $p=0.0001){ }^{81)}$ Another review $^{82)}$ of 5 clinical studies indicated that haloperidol- or risperidone-induced hyperprolactinemia appeared to be abrupt and persistent, and the magnitude of hyperprolactinemia was greater in females than males.

Although some study suggested that there was no gender difference for the effect of PR antipsychotics on prolactin levels, ${ }^{12)}$ in a meta-analysis by Stubbs et al., ${ }^{6)}$ the result of a total of 3,038 schizophrenia patients from nineteen studies pointed out that men were more vulnerable to osteoporosis and osteopenia than women. Another cross- 


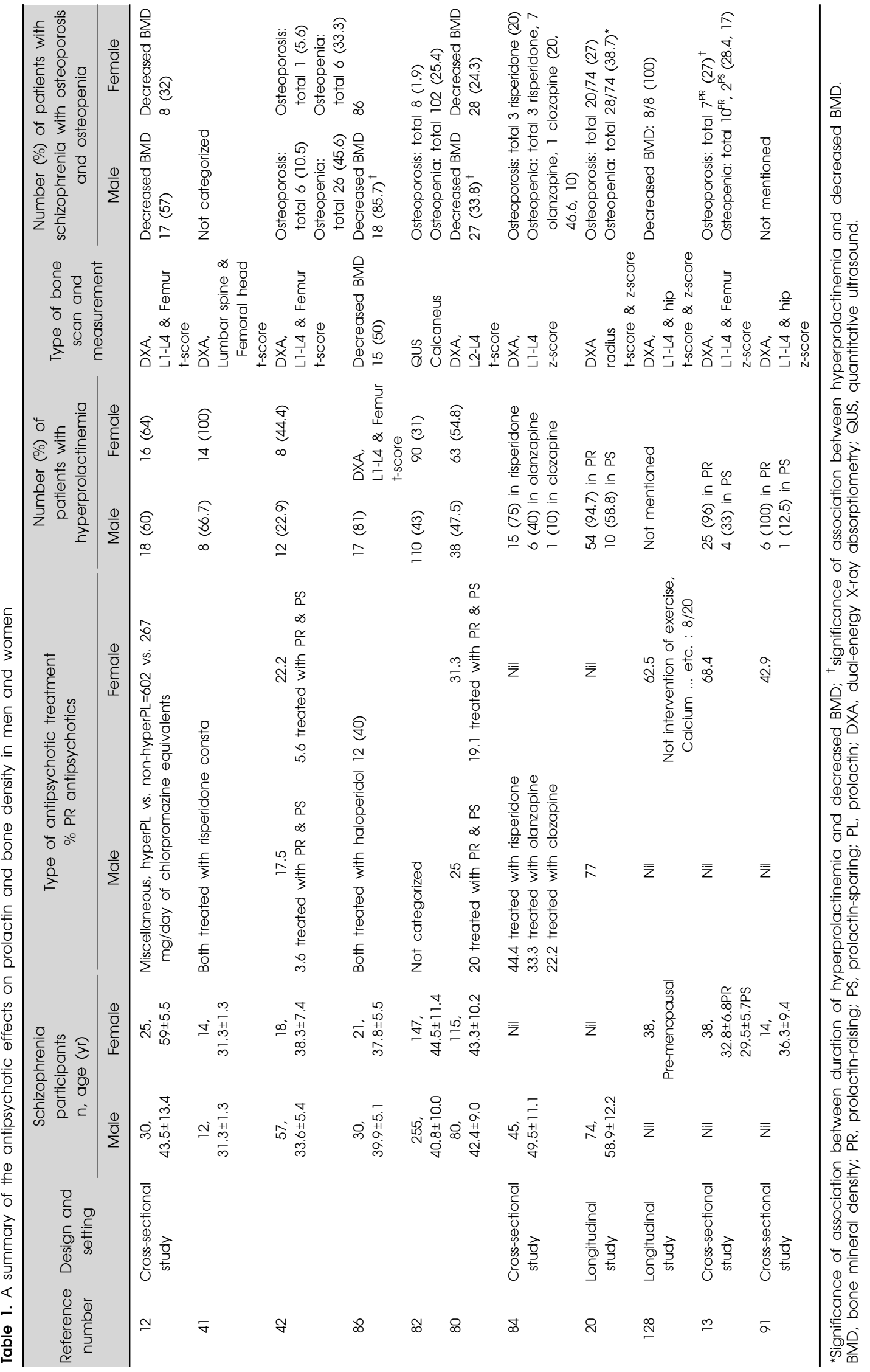


sectional study in 195 Taiwanese schizophrenia patients found that men taking PR antipsychotics tended to have lower BMD than women. ${ }^{79)}$ Male patients with schizophrenia taking antipsychotics for at least 1 year suffered from a lower BMD than did women. ${ }^{42)}$ Furthermore, a longitudinal study of 74 schizophrenia men suggested that the duration of hyperprolactinemia was correlated with the reduction in $\mathrm{BMD}$, whereas the level of prolactin did not directly reflect the extent of BMD loss. ${ }^{20)}$ This conclusion was supported by another prospective study showing that BMD is negatively correlated with longer time periods (more than 12 months) of hyperprolactinemia or affected by prolactin at only much higher levels. ${ }^{13)}$ A crosssectional study followed 45 male patients with schizophrenia who had been receiving antipsychotic monotherapy (risperidone, olanzapine or clozapine) for longterm (more than 20 years) ${ }^{83)}$ The results showed that those patients' BMD were not associated with both their sex hormone level and prolactin level. The study further proposed that the pathophysiology of the decreased BMD among schizophrenic male patient might be different from that of female patients. It also suggested that the effect of negative symptoms might be greater than antipsychotics use on BMD in schizophrenia patients.

A cross-sectional study of 229 schizophrenia patients (93 postmenopausal women and 136 men) who were older than 50 year-old found that postmenopausal women had a significantly higher prevalence of osteoporosis than men $(48.4 \%$ vs. $25.7 \%){ }^{44)}$ An earlier study conducted by the same author proposed that PR antipsychotics-induced hyperprolactinemia was associated with decreased BMD among premenopausal female schizophrenic patients. ${ }^{84)}$ Another cross-sectional study of 71 schizophrenia women showed that bone turnover acceleration was found in all female patients including pre- and post- menopausal women; nevertheless, ${ }^{85)}$ in a longitudinal study, only postmenopausal women were found to have decreased BMD compared to premenopausal women. ${ }^{86)}$ A large scale cross-sectional study involving 6,820 postmenopausal women with schizophrenia suggested that both schizophrenia per se and treatment with atypical antipsychotics were independent risk factors for osteoporotic bone changes. ${ }^{87)}$ Nonetheless, a longitudinal study for old men $>52$ year-old and postmenopausal women of schizophrenia with long-term ( $>10$ years) PR antipsychotics treatment showed that only the dose of antipsychotics (shown in chlorpromazine equivalence index) was associated with decreased BMD in multivariate analysis. ${ }^{12}$

\section{Dose Dependent or Course Dependent}

A previous study showed that decreased BMD was related to the duration of hyperprolactinemia. ${ }^{88)}$ Sustained hyperprolactinemia was found to have an impact on the rate of bone metabolism. ${ }^{89)}$ Researchers had no consensus yet about the effect of antipsychotic dose on prolactin level. A common finding is that lowering the dose of antipsychotics may decrease the prolactin level in subjects with hyperprolactinemia. ${ }^{12,90)}$ Furthermore, antipsychoticinduced hyperprolactinemia is not related to the duration of antipsychotic treatment. ${ }^{91)}$ Besides, there were evidences for both approving ${ }^{20)}$ and opposing ${ }^{22,92)}$ the negative effect of the duration of antipsychotic use on BMD. Together, the association of decreased BMD between antipsychotic dose and duration has not yet been conclusive. ${ }^{36)}$

\section{Gender Difference on Bone Mineral Density of Other Psychotropic Agents}

Many psychotropic drugs have been reported to be associated with the development of BMD loss, including lithium, selective serotonin reuptake inhibitors (SSRIs) and anticonvulsants. ${ }^{11)}$ Earlier studies suggested no effect of lithium on bone structure, ${ }^{93)}$ whereas recent evidences showed protective effect of lithium on BMD. ${ }^{94)}$ A crosssectional study suggested that women taking lithium of therapeutic dose had higher estradiol levels which were correlated with spinal BMD, although the psychiatric illness and combined medications were not controlled in the study. $^{94)}$

SSRIs but not tricyclic antidepressants was found to have negative effect on BMD. ${ }^{87)}$ Chronic administration of SSRIs may increase the risk of osteoporotic fractures. ${ }^{90)}$ A recent review demonstrated that SSRIs negatively affected bone growth by interfering 5-HT transporter in bone cells that leads to bone demineralization and subsequent reduced BMD, and the effect was dosedependent. ${ }^{95)}$ Although studies about the effect of SSRIs on BMD are lacking in schizophrenia patients, SSRIs are indicated to cause decreased BMD in patients with generalized anxiety disorder, especially in those female patients who are older and post-menopausal. ${ }^{96)}$

Anticonvulsants such as carbamazepine and valproic acid which were frequently used as mood stabilizers may also lead to decreased BMD in bipolar disorders. The decrease of BMD was found to be related to the diminished level of 25-hydroxy vitamin D, and this effect was related to duration of anticonvulsants treatment. ${ }^{97)}$ A meta-analysis consisted of more than 907,000 men and women in- 
dicated that the use of beta-blocker was associated with $17 \%$ reduction in the risk of any fracture. ${ }^{98)}$ However, currently there is no reported study about the effect of beta-blocker on BMD in schizophrenia patients.

\section{Biochemical Bone Markers and Other Hormonal Effects}

The subtle change of BMD is hardly to detect by radiologic exam particularly within 3 to 4 years of bone resorption. Nonetheless, biochemical bone markers can serve as more sensitive tests that the change of bone metabolism can be evaluated in a much shorter time (about 2 to 4 weeks) after treatment. ${ }^{99)}$ Various biochemical bone markers have been reported including bone-specific alkaline phosphatase (BAP), osteoclacin (OC), C-terminal or $\mathrm{N}$-terminal propeptides of type I procollagen (PICP or PINP), deoxypyridinoline (DPD), type I collagen releases carboxy-terminally cross-linked telopeptides and amino-terminally cross-linked telopeptides (CTX and NTX), tartrate-resistant acid phosphatase 5b (TRAP5b), bone sialoprotein (BSP), osteopontin (OPN), carboxy-terminal cross-linking telopeptide of type I collagen (ICTP). ${ }^{100)}$ Among those bone markers, BAP and OC are mostly recommended as bone formation markers; and DPD, CTX and NTX as well as collagen fragments as ICTP are regarded as bone resorption markers. ${ }^{101)}$ However, ICTP has a low specificity in reflecting bone absorption, since it may also be correlated with decomposition of other tissue result from physical changes. ${ }^{102,103)}$

Bone turnover markers, including bone formation and bone resorption markers, reflect the bone physiological fluctuations that may be involved in the relationship between antipsychotics use and BMD change. ${ }^{36)}$ Consequently, bone markers may be potentially useful predictor for osteoporosis induced by antipsychotic use. A bone resorption marker TRACP-5b was found negatively related to both testosterone level in men and estradiol level in women with schizophrenia. ${ }^{104)}$ Moreover, the TRACP-5b level was positively correlated with prolactin levels in female patients but not in males.

Leptin, a $16 \mathrm{kDa}$ protein synthesized by adipose tissue, may inhibit bone formation through both peripheral and central ways. ${ }^{105)}$ Leptin acts as a negative feedback signal against absorption of fat. It is also found in lower level in central nervous system of obese people who may induce leptin resistance. ${ }^{106)}$ Meanwhile, obesity, partially related to the side effects of medication and negative symptoms, is very common among patients with schizophrenia. ${ }^{107)}$ Obesity that leads to the resistance to the effects of leptin therefore serves as a protective factor, compensating the low BMD related to hypogonadism and hypercortisolism commonly seen in schizophrenia patients treated with antipsychotics. ${ }^{108,109)}$ Furthermore, it is suggested that leptin could modulate the mesolimbic dopamine system ${ }^{110}$ ) and was thus inversely associated with the severity of positive symptoms in schizophrenia patients. ${ }^{111)}$ A meta-analysis of 28 studies indicated that olanzapine, clozapine and quetiapine may raise leptin levels in patients with schizophrenia. The study suggested that the leptin levels were positively correlated with BMI in the consequence of leptin resistance result from antipsychotics related weight gain and metabolic syndrome. ${ }^{106)}$ There was no gender difference on antipsychotic-induced changes in leptin levels from this meta-analysis. Further studies are needed to clarify the effects of gender on leptin in patients with schizophrenia particularly those with obesity or higher BMD that is more common in postmenopausal women and older men.

\section{Age Differences on BMD}

The cross-sectional study that involved 327 schizophrenia patients implied that $79.9 \%$ of those schizophrenia patients older than 50-year-old had decreased BMD (45.0\% and 34.9\% for osteopenia and osteoporosis, respectively). ${ }^{44)}$ The prevalence of decreased BMD, including osteopenia and osteoporosis, in older schizophrenia patients is higher than that of schizophrenia patients with overall age (53.2\%). ${ }^{6)}$ The prevalence of osteoporosis in elderly patients with schizophrenia is about 2 times as that of healthy individuals of the same age $(34.9 \%$ vs. $18.4 \%$ ). Among patients treated with PR antipsychotics, aging has been reported to be a risk factor of osteopenia for both genders. ${ }^{112)}$ Another research showed that the difference in BMD between schizophrenia patients and controls was not significant until their 30s, and the difference became detectable in their 40 s or older respectively. ${ }^{20)}$

A study in Japan with 362 patients diagnosed as schizophrenia or schizoaffective disorder found that the decrease in BMD was found in men of age 40 years or older and in women of age 60 years or older. ${ }^{113)}$ In both genders of schizophrenic patients in the study, the older group (aged 50 years and older) has significantly lower BMD than the younger group. A more interesting finding of the study was that the effect of age on BMD was more prominent in schizophrenia male than female patients: the rate of age-related BMD loss of male schizophrenia patients was greater than that of male control group, whereas the decline rates of BMD with age were not different between female schizophrenia patients and female control group. 
The main cause of the gender difference might possibly be that the effect of menopause on bone loss exceeded those of other risk factors including antipsychotics use or the disease itself. ${ }^{113)}$

In postmenopausal women, both menopause and hyperprolactinemia lead to hypogonadism that accelerate the decrease of BMD. ${ }^{12,114)}$ The bioavailable estradiol is of particular importance to skeletal health and correlated with BMD change. Evidences support the supplement of exogenous estrogen for the prevention of osteoporotic fractures. ${ }^{69)}$ Testosterone, on the other hand, could also maintain BMD and prevent osteoporotic fracture in postmenopausal women with low estradiol levels. ${ }^{115)}$ Nevertheless, although endogenous testosterone also serves as a protective factor for BMD in postmenopausal women, estrogen seems to play a more important role. ${ }^{116)}$ A recent cross-sectional study in postmenopausal women also indicated that serum testosterone itself did not affect BMD; the effects of testosterone on BMD are dependent of estrogen levels. ${ }^{75)}$ It is likely that the effect of estrogen on BMD is greater than that of testosterone in postmenopausal women.

Some reports revealed that children and adolescents taking antipsychotics also experienced substantial problems of decreased BMD, although those patients were young and only had modest (varying between two- to four-fold) increase of prolactin levels than normal levels. ${ }^{117)}$ The effect of PR antipsychotics on prolactin level may be independent of age, in other words, PR antipsychotics may affect prolactin level in patient at all age. ${ }^{82)}$ Although the peak bone mass is mainly determined by genetic factors, up to $20 \%$ of the variance results from environmental or hormonal factors during puberty. ${ }^{118)}$ The exact effect of hyperprolactinemia on BMD during puberty, a vital period of bone development during which $60 \%$ of bone growth occurs, is unknown; it should be deliberate when treating patients with PR antipsychotics during the adolescent period. ${ }^{13)}$

\section{PROTECTIVE FACTORS FOR BMD}

There are many factors that have shown protective effect on BMD. Vitamin D is one of the protective factors for BMD. ${ }^{119)}$ Pro-vitamin D in the body reacts to ultraviolet light which cannot be replaced by indoor light ${ }^{12)}$ on the surface of the skin and is converted to vitamin D. ${ }^{22)}$ Sufficient calcium intake $(1,200-1,500 \mathrm{mg} /$ day $)$ is also vital for the prevention and treatment of osteoporosis. ${ }^{120)}$ Dopamine agonist may also serve as a protecting factor to restore normal menstrual function and increase BMD among the hyperprolactinemic women with amenorrhea. ${ }^{121)}$ Exercise is among the well-known protective factors for BMD. In detail, light exercise can stimulate the growth of bone cells ${ }^{79)}$ while weight-bearing exercise may work against bone demineralization. ${ }^{122)}$ It is well-known that long term use of many psychotropic drugs, such as amitriptyline, mirtazapine and the second-generation antipsychotics including clozapine, olanzapine, quetiapine and risperidone may cause weight gain. ${ }^{123,124)}$ Since modest increase in BMI can enhance BMD, ${ }^{125)}$ weight gain that results from medication effect may possibly act as a protecting role against BMD loss especially for patients receiving PR antipsychotics. ${ }^{41)}$ Besides, a study of chronic schizophrenia women indicated that clozapine may protect BMD by activating N-methyl-D-aspartate receptors on osteoblast with dose-related effect. ${ }^{126)}$ Recent study about the receptor activator of NF- $\mathrm{KB}$ ligand (RANKL) showed that quetiapine can inhibit RANKL-induced osteoclast differentiation and decrease cancer-associated bone resorption. ${ }^{127)}$ Another animal study in 2011 also pointed out the effect of phenothiazines such as chlorpromazine, trifluoperazine, and promethazine inhibited inhibit RANKL-induced osteoclastogenesis through anti-CaM action (CaM, calmodulin, a intracellular calciumreceptive protein actions). ${ }^{128)}$

As aforementioned, resistance to leptin may be a protecting factor against the decrease of BMD. This hypothesis was supported by an animal study in which the mice with leptin or leptin receptor deficiency could maintain high BMD despite of hypogonadism, suggesting that the high BMD was the consequence of the paucity of leptin signaling, not of obesity. ${ }^{108)}$ Interventions to improve the bone density, such as calcium or vitamin D supplement, octacalcium phosphate (a precursor of bone apatite crystals) and exercise were demonstrated to be helpful for enhancing BMD in schizophrenia women taking either PS or PR antipsychotics; however, the effect of these interventions in improving BMD was found significant only in women who were treated with PS antipsychotics. ${ }^{129)}$

For disease-specific factors, positive symptom that may lead to increased psychomotor activity was reported to be a protecting factor of BMD in women with schizophrenia. ${ }^{130)}$ For male schizophrenia patients, the score of Global Assessment of Functioning (GAF) was found to be correlated with the exercise capacity that might be a positive predictor of BMD. ${ }^{131)}$ 


\section{SUMMARY}

Osteoporosis and the subsequent comorbidities lead to poor outcome and quality of life in patients with schizophrenia, particularly those taking antipsychotic drugs. Decreased BMD was found in more than half of all schizophrenia patients, and its prevalence was significantly higher than normal population. The effect of hyperprolactinemia on BMD is inconclusive. Antipsychoticsinduced hyperprolactinemia is more common in female schizophrenia patients. However, current evidences show that postmenopausal women and older men were more vulnerable to hyperprolactinemia-related low BMD than premenopausal women and younger men. In addition to antipsychotic drugs and possibly associated hyperprolactinemia effects, there are many other factors that can affect BMD in patients with schizophrenia, including medications such as lithium, SSRIs and anticonvulsants, sex hormones, body weight, life style, negative symptoms, inadequate nutrition $\cdots$ etc. This review discussed the gender differences about the effect of these risk factors on BMD in patients with schizophrenia.

On the issue of the effect of PR antipsychotics-related hyperprolactinemia on BMD, evidences from previous studies were inconclusive. The inconsistent findings among studies might partially result from the cross-sectional study design and lack of adequate control groups. Certain questions remain unanswered by present literatures. This review on BMD in patients with schizophrenia is limited by the insufficient prospective studies on the topic of gender differences. Prospective studies with larger sample size and adequate controls are required in the future for elucidating the unsolved issues. This review points out that gender differences exist in various aspects regarding the decreased BMD in patients with schizophrenia. Physicians should pay attention to gender differences in treating low BMD in order to formulate specific prevention and therapeutic strategies for different populations.

\section{Acknowledgments}

This work was funded by Chang Gung Memorial Hospital (Taiwan) CMRPG8D0051. The aforementioned institute had no further role in the writing of the report, and in the decision to submit the paper for publication. All authors declare that they have no conflicts of interest.

\section{REFERENCES}

1. Hugenholtz GW, Heerdink ER, van Staa TP, Nolen WA, Egberts AC. Risk of hip/femur fractures in patients using antipsychotics. Bone 2005;37:864-870.

2. Howard L, Kirkwood G, Leese M. Risk of hip fracture in patients with a history of schizophrenia. Br J Psychiatry 2007:190:129-134.

3. Takahashi T, Uchida H, John M, Hirano J, Watanabe K, Mimura M, et al. The impact of prolactin-raising antipsychotics on bone mineral density in patients with schizophrenia: findings from a longitudinal observational cohort. Schizophr Res 2013;147:383-386.

4. Stubbs B, Gaughran F, Mitchell AJ, De Hert M, Farmer $\mathrm{R}$, Soundy A, et al. Schizophrenia and the risk of fractures: a systematic review and comparative meta-analysis. Gen Hosp Psychiatry 2015;37:126-133.

5. Holt RI. Osteoporosis in people with severe mental illness: A forgotten condition. Maturitas 2010;67:1-2.

6. Stubbs B, De Hert M, Sepehry AA, Correll CU, Mitchell AJ, Soundy A, et al. A meta-analysis of prevalence estimates and moderators of low bone mass in people with schizophrenia. Acta Psychiatr Scand 2014;130:470-486.

7. Javaid MK, Holt RI. Understanding osteoporosis. J Psychopharmacol 2008;22(2 Suppl):38-45.

8. Simon JA, Mack CJ. Prevention and management of osteoporosis. Clin Cornerstone 2003;Suppl 2:S5-S12.

9. Lorentzon M, Cummings SR. Osteoporosis: the evolution of a diagnosis. J Intern Med 2015;277:650-661.

10. Golob AL, Laya MB. Osteoporosis: screening, prevention, and management. Med Clin North Am 2015;99:587-606.

11. Kanis JA. Assessment of fracture risk and its application to screening for postmenopausal osteoporosis: synopsis of a WHO report. WHO Study Group. Osteoporos Int 1994; 4:368-381.

12. Meaney AM, Smith S, Howes OD, O'Brien M, Murray $\mathrm{RM}$, O'Keane V. Effects of long-term prolactin-raising antipsychotic medication on bone mineral density in patients with schizophrenia. Br J Psychiatry 2004;184:503-508.

13. O'Keane V, Meaney AM. Antipsychotic drugs: a new risk factor for osteoporosis in young women with schizophrenia? J Clin Psychopharmacol 2005;25:26-31.

14. Renn JH, Yang NP, Chueh CM, Lin CY, Lan TH, Chou P. Bone mass in schizophrenia and normal populations across different decades of life. BMC Musculoskelet Disord 2009; 10:1

15. Gudelsky GA. Tuberoinfundibular dopamine neurons and the regulation of prolactin secretion. Psychoneuroendocrinology 1981;6:3-16.

16. Peveler RC, Branford D, Citrome L, Fitzgerald P, Harvey PW, Holt RI, et al. Antipsychotics and hyperprolactinaemia: clinical recommendations. J Psychopharmacol 2008;22(2 Suppl):98-103.

17. Kollin E, Gergely I, Szücs J, Holló I. Decreased bone density in hyperprolactinemic women. $N$ Engl $J$ Med 1981;304:1362-1363.

18. Dickson RA, Seeman MV, Corenblum B. Hormonal side effects in women: typical versus atypical antipsychotic treatment. J Clin Psychiatry 2000;61 Suppl 3:10-15.

19. Klibanski A, Biller BM, Rosenthal DI, Schoenfeld DA, Saxe V. Effects of prolactin and estrogen deficiency in amenorrheic bone loss. J Clin Endocrinol Metab 1988;67: 124-130.

20. Kishimoto T, Watanabe K, Shimada N, Makita K, Yagi G, Kashima H. Antipsychotic-induced hyperprolactinemia inhibits the hypothalamo-pituitary-gonadal axis and reduces bone mineral density in male patients with schizophrenia. $J$ Clin Psychiatry 2008;69:385-391.

21. Khosla S, Oursler MJ, Monroe DG. Estrogen and the 
skeleton. Trends Endocrinol Metab 2012;23:576-581.

22. Kinon BJ, Ahl J, Liu-Seifert H, Maguire GA. Improvement in hyperprolactinemia and reproductive comorbidities in patients with schizophrenia switched from conventional antipsychotics or risperidone to olanzapine. Psychoneuroendocrinology 2006;31:577-588.

23. Riggs BL, Melton LJ 3rd. Involutional osteoporosis. $N$ Engl J Med 1986;314:1676-1686.

24. Kenny AM, Prestwood KM. Osteoporosis. Pathogenesis, diagnosis, and treatment in older adults. Rheum Dis Clin North Am 2000;26:569-591.

25. Seriwatanachai D, Krishnamra N, van Leeuwen JP. Evidence for direct effects of prolactin on human osteoblasts: Inhibition of cell growth and mineralization. J Cell Biochem 2009;107:677-685.

26. Kanis JA, Johnell O, Oden A, Johansson H, De Laet C, Eisman JA, et al. Smoking and fracture risk: a metaanalysis. Osteoporos Int 2005;16:155-162.

27. Gonnelli S, Caffarelli C, Nuti R. Obesity and fracture risk. Clin Cases Miner Bone Metab 2014;11:9-14.

28. Chesnut $\mathrm{CH}$ 3rd. Bone mass and exercise. Am J Med 1993;95:34S-36S.

29. Holbrook TL, Barrett-Connor E. A prospective study of alcohol consumption and bone mineral density. BMJ 1993;306:1506-1509.

30. Cooper MS, Seibel MJ, Zhou H. Glucocorticoids, bone and energy metabolism. Bone 2016;82:64-68.

31. Pocock NA, Eisman JA, Hopper JL, Yeates MG, Sambrook PN, Eberl S. Genetic determinants of bone mass in adults. A twin study. J Clin Invest 1987;80:706-710.

32. Burge RT, Worley D, Johansen A, Bhattacharyya S, Bose $\mathrm{U}$. The cost of osteoporotic fractures in the UK: projections for 2000-2020. J Med Econ 2001;4:51-62.

33. Peet M. Diet, diabetes and schizophrenia: review and hypothesis. Br J Psychiatry Suppl 2004;47:S102-S105.

34. Wark JD. Osteoporotic fractures: background and prevention strategies. Maturitas 1996;23:193-207.

35. Crews MP, Howes OD. Is antipsychotic treatment linked to low bone mineral density and osteoporosis? A review of the evidence and the clinical implications. Hum Psychopharmacol 2012;27:15-23.

36. Kishimoto T, De Hert M, Carlson HE, Manu P, Correll $\mathrm{CU}$. Osteoporosis and fracture risk in people with schizophrenia. Curr Opin Psychiatry 2012;25:415-429.

37. Soundy A, Wampers M, Probst M, De Hert M, Stubbs B, Vancampfort $\mathrm{D}$, et al. Physical activity and sedentary behaviour in outpatients with schizophrenia: A systematic review and meta-analysis. Int $J$ Ther Rehabil 2013;20: 588-595.

38. DE Hert M, Correll CU, Bobes J, Cetkovich-Bakmas M, Cohen D, Asai I, et al. Physical illness in patients with severe mental disorders. I. Prevalence, impact of medications and disparities in health care. World Psychiatry 2011:10:52-77.

39. Vancampfort D, Wampers M, Mitchell AJ, Correll CU, De Herdt A, Probst M, et al. A meta-analysis of cardiometabolic abnormalities in drug naïve, first-episode and multi-episode patients with schizophrenia versus general population controls. World Psychiatry 2013;12:240-250.

40. Delva NJ, Crammer JL, Jarzylo SV, Lawson JS, Owen JA, Sribney M, et al. Osteopenia, pathological fractures, and increased urinary calcium excretion in schizophrenic patients with polydipsia. Biol Psychiatry 1989;26:781-793.

41. Doknic M, Maric NP, Britvic D, Pekic S, Damjanovic A, Miljic D, et al. Bone remodeling, bone mass and weight gain in patients with stabilized schizophrenia in real-life conditions treated with long-acting injectable risperidone. Neuroendocrinology 2011;94:246-254.

42. Hummer M, Malik P, Gasser RW, Hofer A, Kemmler G, Moncayo Naveda RC, et al. Osteoporosis in patients with schizophrenia. Am J Psychiatry 2005;162:162-167.

43. de Leon J, Diaz FJ. A meta-analysis of worldwide studies demonstrates an association between schizophrenia and tobacco smoking behaviors. Schizophr Res 2005;76:135157.

44. Jung DU, Kelly DL, Oh MK, Kong BG, Kang JW, Lee $\mathrm{SJ}$, et al. Bone mineral density and osteoporosis risk in older patients with schizophrenia. J Clin Psychopharmacol 2011;31:406-410.

45. Yoon V, Maalouf NM, Sakhaee K. The effects of smoking on bone metabolism. Osteoporos Int 2012;23:2081-2092.

46. Kessler RC, Birnbaum H, Demler O, Falloon IR, Gagnon $\mathrm{E}$, Guyer $\mathrm{M}$, et al. The prevalence and correlates of nonaffective psychosis in the National Comorbidity Survey Replication (NCS-R). Biol Psychiatry 2005;58:668-676.

47. Sampson HW. Alcohol's harmful effects on bone. Alcohol Health Res World 1998;22:190-194.

48. Janghorbani M, Van Dam RM, Willett WC, Hu FB. Systematic review of type 1 and type 2 diabetes mellitus and risk of fracture. Am J Epidemiol 2007;166:495-505.

49. Dazzan P, Murray RM. Neurological soft signs in firstepisode psychosis: a systematic review. Br J Psychiatry Suppl 2002;43:s50-s57.

50. Partti K, Heliövaara M, Impivaara O, Perälä J, Saarni SI, Lönnqvist $\mathrm{J}$, et al. Skeletal status in psychotic disorders: a population-based study. Psychosom Med 2010;72:933940.

51. NIH Consensus Development Panel on Osteoporosis Prevention, Diagnosis, and Therapy, March 7-29, 2000: highlights of the conference. South Med J 2001;94:569-573.

52. Bonnick SL. Bone densitometry in clinical practice: application and interpretation. New York, NY:Humana Press; 2010.

53. Czerwiński E. [Radiologic diagnosis and densitometry of osteoporosis]. Przegl Lek 1997;54:220-225. Polish.

54. Kanis JA. Diagnosis of osteoporosis and assessment of fracture risk. Lancet 2002;359:1929-1936.

55. Leslie WD, Adler RA, El-Hajj Fuleihan G, Hodsman AB, Kendler DL, McClung M, et al; International Society for Clinical Densitometry. Application of the 1994 WHO classification to populations other than postmenopausal Caucasian women: the 2005 ISCD Official Positions. J Clin Densitom 2006;9:22-30.

56. Binkley N, Bilezikian JP, Kendler DL, Leib ES, Lewiecki EM, Petak SM; International Society for Clinical Densitometry. Official positions of the International Society for Clinical Densitometry and Executive Summary of the 2005 Position Development Conference. J Clin Densitom 2006; 9:4-14.

57. Heidari B, Khashayar P, Rezai Homami M, Pajouhi A, Soltani A, Larijani B. Dual-energy X-ray absorptiometry diagnostic discordance between Z-scores and T-scores in a young Iranian population. Med J Islam Repub Iran 2014:28:151.

58. Swaminathan K, Flynn R, Garton M, Paterson C, Leese G. Search for secondary osteoporosis: are Z scores useful predictors? Postgrad Med J 2009;85:38-39.

59. Carey JJ, Delaney MF, Love TE, Richmond BJ, Cromer $\mathrm{BA}$, Miller PD, et al. DXA-generated Z-scores and T-scores may differ substantially and significantly in young 
adults. J Clin Densitom 2007;10:351-358.

60. Gilsanz V, Gibbens DT, Carlson M, Boechat MI, Cann CE, Schulz EE. Peak trabecular vertebral density: a comparison of adolescent and adult females. Calcif Tissue Int 1988;43:260-262.

61. Farr JN, Khosla S. Skeletal changes through the lifespan-from growth to senescence. Nat Rev Endocrinol 2015;11: 513-521.

62. Ferlin A, Selice R, Carraro U, Foresta C. Testicular function and bone metabolism--beyond testosterone. Nat Rev Endocrinol 2013;9:548-554.

63. Mellström D, Vandenput L, Mallmin H, Holmberg AH, Lorentzon M, Odén A, et al. Older men with low serum estradiol and high serum $S H B G$ have an increased risk of fractures. J Bone Miner Res 2008;23:1552-1560.

64. Amin S, Zhang Y, Felson DT, Sawin CT, Hannan MT, Wilson PW, et al. Estradiol, testosterone, and the risk for hip fractures in elderly men from the Framingham Study. Am J Med 2006;119:426-433.

65. Goderie-Plomp HW, van der Klift M, de Ronde W, Hofman A, de Jong FH, Pols HA. Endogenous sex hormones, sex hormone-binding globulin, and the risk of incident vertebral fractures in elderly men and women: the Rotterdam Study. J Clin Endocrinol Metab 2004;89:3261-3269.

66. Falahati-Nini A, Riggs BL, Atkinson EJ, O'Fallon WM, Eastell R, Khosla S. Relative contributions of testosterone and estrogen in regulating bone resorption and formation in normal elderly men. J Clin Invest 2000;106:1553-1560.

67. Hannemann A, Breer S, Wallaschofski H, Nauck M, Baumeister SE, Barvencik F, et al. Osteocalcin is associated with testosterone in the general population and selected patients with bone disorders. Andrology 2013;1:469-474.

68. Barrett-Connor E, Laughlin GA, Li H, Nielson CM, Wang PY, Dam TT, et al; Osteoporotic Fractures in Men (MrOS) Research Group. The association of concurrent vitamin D and sex hormone deficiency with bone loss and fracture risk in older men: the osteoporotic fractures in men (MrOS) study. J Bone Miner Res 2012;27:2306-2313.

69. Cauley JA. Estrogen and bone health in men and women. Steroids 2015;99:11-15.

70. Irwig MS. Bone health in hypogonadal men. Curr Opin Urol 2014;24:608-613.

71. Watts NB, Adler RA, Bilezikian JP, Drake MT, Eastell R, Orwoll ES, et al; Endocrine Society. Osteoporosis in men: an Endocrine Society clinical practice guideline. J Clin Endocrinol Metab 2012;97:1802-1822.

72. Yarrow JF, Wronski TJ, Borst SE. Testosterone and adult male bone: Actions independent of 5 a-reductase and aromatase. Exerc Sport Sci Rev 2015;43:222-230.

73. Smith EP, Boyd J, Frank GR, Takahashi H, Cohen RM, Specker B, et al. Estrogen resistance caused by a mutation in the estrogen-receptor gene in a man. $N$ Engl J Med 1994;331:1056-1061.

74. Morishima A, Grumbach MM, Simpson ER, Fisher C, Qin $\mathrm{K}$. Aromatase deficiency in male and female siblings caused by a novel mutation and the physiological role of estrogens. J Clin Endocrinol Metab 1995;80:3689-3698.

75. Arpaci D, Saglam F, Cuhaci FN, Ozdemir D, Ersoy R, Cakir B. Serum testosterone does not affect bone mineral density in postmenopausal women. Arch Endocrinol Metab 2015; 59:292-296.

76. Khosla S, Melton LJ 3rd, Atkinson EJ, O'Fallon WM, Klee GG, Riggs BL. Relationship of serum sex steroid levels and bone turnover markers with bone mineral density in men and women: a key role for bioavailable estrogen. $J$
Clin Endocrinol Metab 1998;83:2266-2274.

77. Kalantaridou SN, Calis KA. Testosterone therapy in premenopausal women. Semin Reprod Med 2006;24:106114.

78. Hummer M, Huber J. Hyperprolactinaemia and antipsychotic therapy in schizophrenia. Curr Med Res Opin 2004;20: 189-197.

79. Lin CH, Lin CY, Huang TL, Wang HS, Chang YC, Lane HY. Sex-specific factors for bone density in patients with schizophrenia. Int Clin Psychopharmacol 2015;30:96-102.

80. Bushe C, Shaw M, Peveler RC. A review of the association between antipsychotic use and hyperprolactinaemia. J Psychopharmacol 2008;22(2 Suppl):46-55.

81. Kinon BJ, Liu-Seifert H, Stauffer VL, Jacob J. Bone loss associated with hyperprolactinemia in patients with schizophrenia. Clin Schizophr Relat Psychoses 2013;7:115-123.

82. Kinon BJ, Gilmore JA, Liu H, Halbreich UM. Hyperprolactinemia in response to antipsychotic drugs: characterization across comparative clinical trials. Psychoneuroendocrinology 2003;28 Suppl 2:69-82.

83. Lee TY, Chung MY, Chung HK, Choi JH, Kim TY, So HS. Bone density in chronic schizophrenia with long-term antipsychotic treatment: preliminary study. Psychiatry Investig 2010; 7:278-284.

84. Jung DU, Conley RR, Kelly DL, Kim DW, Yoon SH, Jang $\mathrm{JH}$, et al. Prevalence of bone mineral density loss in Korean patients with schizophrenia: a cross-sectional study. J Clin Psychiatry 2006;67:1391-1396.

85. Bergemann N, Parzer P, Mundt C, Auler B. High bone turnover but normal bone mineral density in women suffering from schizophrenia. Psychol Med 2008;38:11951201 .

86. Wei QS, Huang L, Tan X, Chen ZQ, Chen SM, Deng WM. Serum osteopontin levels in relation to bone mineral density and bone turnover markers in postmenopausal women. Scand J Clin Lab Invest 2016;76:33-39.

87. Bolton JM, Targownik LE, Leung S, Sareen J, Leslie WD. Risk of low bone mineral density associated with psychotropic medications and mental disorders in postmenopausal women. J Clin Psychopharmacol 2011;31:56-60.

88. Greenspan SL, Neer RM, Ridgway EC, Klibanski A. Osteoporosis in men with hyperprolactinemic hypogonadism. Ann Intern Med 1986;104:777-782.

89. Abraham G, Paing WW, Kaminski J, Joseph A, Kohegyi $\mathrm{E}$, Josiassen RC. Effects of elevated serum prolactin on bone mineral density and bone metabolism in female patients with schizophrenia: a prospective study. Am J Psychiatry 2003;160:1618-1620.

90. Masi G, Cosenza A, Mucci M. Prolactin levels in young children with pervasive developmental disorders during risperidone treatment. J Child Adolesc Psychopharmacol 2001;11:389-394.

91. Paparrigopoulos T, Liappas J, Tzavellas E, Mourikis I, Soldatos C. Amisulpride-induced hyperprolactinemia is reversible following discontinuation. Prog Neuropsychopharmacol Biol Psychiatry 2007;31:92-96.

92. Kearns AE, Goff DC, Hayden DL, Daniels GH. Risperidone-associated hyperprolactinemia. Endocr Pract 2000;6:425-429.

93. Plenge P, Rafaelsen OJ. Lithium effects on calcium, magnesium and phosphate in man: effects on balance, bone mineral content, faecal and urinary excretion. Acta Psychiatr Scand 1982;66:361-373.

94. Zamani A, Omrani GR, Nasab MM. Lithium's effect on bone mineral density. Bone 2009;44:331-334. 
95. Kerbage H, Bahadori S, Léger J, Carel JC, Purper Ouakil D. [Effect of SSRIs on bone metabolism]. Encephale 2014;40:56-61. French.

96. Ak E, Bulut SD, Bulut S, Akdağ HA, Öter GB, Kaya H, et al. Evaluation of the effect of selective serotonin reuptake inhibitors on bone mineral density: an observational cross-sectional study. Osteoporos Int 2015;26:273-279.

97. Misra M, Papakostas GI, Klibanski A. Effects of psychiatric disorders and psychotropic medications on prolactin and bone metabolism. J Clin Psychiatry 2004;65:1607-1618; quiz 1590, 1760-1761.

98. Yang S, Nguyen ND, Eisman JA, Nguyen TV. Association between beta-blockers and fracture risk: a Bayesian meta-analysis. Bone 2012;51:969-974.

99. Bjarnason NH, Christiansen C. Early response in biochemical markers predicts long-term response in bone mass during hormone replacement therapy in early postmenopausal women. Bone 2000;26:561-569.

100. Zaitseva OV, Shandrenko SG, Veliky MM. Biochemical markers of bone collagen type I metabolism. Ukr Biochem J 2015;87:21-32.

101. Christenson RH. Biochemical markers of bone metabolism: an overview. Clin Biochem 1997;30:573-593.

102. Tanaka K, Shiraishi K, Sakamoto A, Jojima H, Masuchi $\mathrm{K}$, Okubo $\mathrm{Y}$, et al. [Serum levels of carboxyterminal propeptide of type I procollagen (PICP), cross-linked carboxyterminal telopeptide region of type I collagen (ICTP) and carboxyterminal parathyroid hormone-related protein $(C-P T H r P)$ in hematological malignancies with bone lesions and hypercalcemia]. Rinsho Ketsueki 1998; 39:273-280. Japan.

103. Fukunaga M. Bone quality and bone metabolism (marker). Clin Calcium 2004;14:561-565.

104. Okita K, Kanahara N, Nishimura M, Yoshida T, YasuiFurukori N, Niitsu T, et al. Second-generation antipsychotics and bone turnover in schizophrenia. Schizophr Res 2014; 157:137-141.

105. Chen XX, Yang T. Roles of leptin in bone metabolism and bone diseases. J Bone Miner Metab 2015;33:474-485.

106. Potvin S, Zhornitsky S, Stip E. Antipsychotic-induced changes in blood levels of leptin in schizophrenia: a metaanalysis. Can J Psychiatry 2015;60(3 Suppl 2):S26-S34.

107. Ventriglio A, Gentile A, Stella E, Bellomo A. Metabolic issues in patients affected by schizophrenia: clinical characteristics and medical management. Front Neurosci 2015;9:297.

108. Ducy P, Amling M, Takeda S, Priemel M, Schilling AF, Beil FT, et al. Leptin inhibits bone formation through a hypothalamic relay: a central control of bone mass. Cell 2000;100:197-207.

109. Yadav VK, Oury F, Suda N, Liu ZW, Gao XB, Confavreux $\mathrm{C}$, et al. A serotonin-dependent mechanism explains the leptin regulation of bone mass, appetite, and energy expenditure. Cell 2009;138:976-989.

110. Leinninger GM, Jo YH, Leshan RL, Louis GW, Yang H, Barrera JG, et al. Leptin acts via leptin receptor-expressing lateral hypothalamic neurons to modulate the mesolimbic dopamine system and suppress feeding. Cell Metab 2009;10:89-98.

111. Takayanagi Y, Cascella NG, Santora D, Gregory PE, Sawa A, Eaton WW. Relationships between serum leptin level and severity of positive symptoms in schizophrenia. Neurosci Res 2013;77:97-101.

112. Liu-Seifert H, Kinon BJ, Ahl J, Lamberson S. Osteopenia associated with increased prolactin and aging in psychiatric patients treated with prolactin-elevating antipsychotics. Ann N Y Acad Sci 2004;1032:297-298.

113. Sugawara N, Yasui-Furukori N, Umeda T, Tsuchimine S, Fujii A, Sato Y, et al. Effect of age and disease on bone mass in Japanese patients with schizophrenia. Ann Gen Psychiatry 2012;11:5.

114. Assessment of fracture risk and its application to screening for postmenopausal osteoporosis. Report of a WHO Study Group. World Health Organ Tech Rep Ser 1994;843:1-129.

115. Rariy CM, Ratcliffe SJ, Weinstein R, Bhasin S, Blackman $\mathrm{MR}$, Cauley JA, et al. Higher serum free testosterone concentration in older women is associated with greater bone mineral density, lean body mass, and total fat mass: the cardiovascular health study. J Clin Endocrinol Metab 2011;96:989-996.

116. Paxton RJ, King DW, Garcia-Prieto C, Connors SK, Hernandez M, Gor BJ, et al. Associations between body size and serum estradiol and sex hormone-binding globulin levels in premenopausal African American women. J Clin Endocrinol Metab 2013;98:E485-E490.

117. Pappagallo M, Silva R. The effect of atypical antipsychotic agents on prolactin levels in children and adolescents. $J$ Child Adolesc Psychopharmacol 2004;14:359-371.

118. Colao A, Di Somma C, Loche S, Di Sarno A, Klain M, Pivonello R, et al. Prolactinomas in adolescents: persistent bone loss after 2 years of prolactin normalization. Clin Endocrinol (Oxf) 2000;52:319-327.

119. Cranney A, Horsley T, O'Donnell S, Weiler H, Puil L, Ooi $\mathrm{D}$, et al. Effectiveness and safety of vitamin $D$ in relation to bone health. Evid Rep Technol Assess (Full Rep) 2007;(158):1-235.

120. Howes OD, Smith S, Aitchison KJ. Comment on Hyperprolactinaemia and antipsychotic therapy in schizophrenia. Curr Med Res Opin 2004;20:1649.

121. Hamner M. The effects of atypical antipsychotics on serum prolactin levels. Ann Clin Psychiatry 2002;14:163-173.

122. Klibanski A, Neer RM, Beitins IZ, Ridgway EC, Zervas NT, McArthur JW. Decreased bone density in hyperprolactinemic women. $N$ Engl J Med 1980;303:1511-1514.

123. Gentile S. Contributing factors to weight gain during long-term treatment with second-generation antipsychotics. A systematic appraisal and clinical implications. Obes Rev 2009; 10:527-542.

124. Domecq JP, Prutsky G, Leppin A, Sonbol MB, Altayar O, Undavalli C, et al. Clinical review: Drugs commonly associated with weight change: a systematic review and meta-analysis. J Clin Endocrinol Metab 2015;100:363-370.

125. Bainbridge KE, Sowers M, Lin X, Harlow SD. Risk factors for low bone mineral density and the 6-year rate of bone loss among premenopausal and perimenopausal women. Osteoporos Int 2004;15:439-446.

126. Lin CH, Huang KH, Chang YC, Huang YC, Hsu WC, Lin $\mathrm{CY}$, et al. Clozapine protects bone mineral density in female patients with schizophrenia. Int $J$ Neuropsychopharmacol 2012;15:897-906.

127. Wang H, Shen W, Hu X, Zhang Y, Zhuo Y, Li T, et al. Quetiapine inhibits osteoclastogenesis and prevents human breast cancer-induced bone loss through suppression of the RANKL-mediated MAPK and NF- $\kappa B$ signaling pathways. Breast Cancer Res Treat 2015;149:705-714.

128. Kawamura H, Arai M, Togari A. Inhibitory effect of chlorpromazine on RANKL-induced osteoclastogenesis in mouse bone marrow cells. J Pharmacol Sci 2011;117: 54-62.

129. Meaney AM, O'Keane V. Bone mineral density changes 
over a year in young females with schizophrenia: relationship to medication and endocrine variables. Schizophr Res 2007;93:136-143.

130. Walther S, Koschorke P, Horn H, Strik W. Objectively measured motor activity in schizophrenia challenges the validity of expert ratings. Psychiatry Res 2009;169:187-190. 131. Vancampfort D, Probst M, Scheewe T, Knapen J, De Herdt A, De Hert M. The functional exercise capacity is correlated with global functioning in patients with schizophrenia. Acta Psychiatr Scand 2012;125:382-387. 